\title{
Does Social Media Influence Consumer Buying Behavior? An Investigation Of Recommendations And Purchases
}

Lukas P. Forbes, Ph.D., Western Kentucky University, USA Eve M. Vespoli, MBA, USA

\begin{abstract}
This research investigates consumers who made a purchase of an item based on the recommendation of a peer or contact via social media (e.g., Facebook; Twitter). Using a sample of 249 consumer purchases, this research analyzes the type of product purchased, the cost of the item, and numerous other product dimensions related to the purchase. Results of the study, along with direction for future research, are presented.
\end{abstract}

Keywords: Social Media; Product Recommendation; Services Marketing; Opinion Leader; Twitter; Facebook

\section{INTRODUCTION}

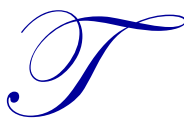

he growth of social media within the United States and the world has been nothing less than astounding. It is estimated that over 500 Million humans internationally are interacting with a social media outlet like Facebook or Twitter on a recurring basis (Ostrow 2010). A key business component of social media is that it now allows consumers to evaluate product, make recommendations to contacts or friends, and link current purchases to future purchases through status updates and twitter feeds. In addition, the use of social media presents a valuable tool for firms in which a satisfied user of a product could recommend that product (good or service) to other potential users. In essence, the social media world is slowly taking the place of product reviews and panels found in outlets such as "Consumer Digest" in previous generations. Where consumers once patronized trusted retails outlets like Sears, because they would find employee experts in each department, today's consumers might often be relying on the recommendation and expert opinion of a friend or acquaintance found within their social media network. What is not known in today's research literature, however, is the extent of the role that social media plays in this recommendation process.

The purpose of this research, therefore, is to investigate the types and characteristics of products that are being recommended and purchased by social media users. For this study, we collected interviews of 249 consumers who made a purchase based on a social media recommendation. Data was collected to investigate numerous purchase decisions to include type of product purchased, the relationship between the buyer and recommender, and the purchasing method and process.

This paper is organized as follows. First, we present our study and our collection methods. Second, using a form of the critical incident technique, we present our findings. Finally, we discuss directions for future research and limitations of our study.

\section{BACKGROUND}

The advent of social media in forms similar to Twitter and Facebook are beginning to have large implications on business practices and academic literature alike. Over the last few years, many academic research papers have investigated the role of social media in the business world. Twitter has been analyzed to look at the role it plays in a variety of marketing areas to include helping brand and promote businesses (Greer and Ferguson 2001) 
to impacting political races (Towner and Dulio 2012). Facebook, the most popular form of social media, has been analyzed in fields ranging from the role of Facebook in increasing a brand or firm's value (Plangger 2012) to fundraising initiatives (Vericat 2010). Even less popular social media forms such as LinkedIn have been investigated in fields such as the role it plays in micro-level dissemination of business information (Ojala 2012). Our research furthers this new area of academic research by investigating product recommendations via social media.

\section{METHODOLOGY}

The intention of this research was to obtain customer responses of their experiences purchasing a product that they bought based on the recommendation of social media contacts and friends. Trained interviewers were sent into the field and tasked to find consumers who had purchased an item based on the recommendation of a social media posting. Interviewers were students in a college level course, and they received course points for writing an analysis of their respondents (not the entire list of respondents). Interviewers worked in teams, and were tasked to find 5 to 15 individuals who had made a purchase based on a social media recommendation of a friend using a version of the critical incident technique (Flanagan 1954). Respondents were stratified by age and gender to ensure a wider range of consumers. In total, 249 consumers participated in this study. The median age of the population was 28 years old, and $59.1 \%$ of the respondents were women.

During the course of the research interview process, respondents were asked to respond to a series of questions geared at understanding the role and influence that various types of social media might have on the purchase behavior of a consumer. In short, our primary research objective was to understand the role that social media plays in product recommendations, product purchases, and dimensions of both of those activities.

Specifically, the following topics were addressed using a series of probing research questions:

- How often does the consumer use a social media service?

- Which type of social media is most used?

- What type of product did the consumer see as recommended (size, type, good or service, color, cost, etc.)?

- How did the recommendation take place? In what format?

- $\quad$ How much did the recommendation influence the consumer's decision to purchase?

- Was it something that the consumer would have purchased anyway?

- Did the recommender influence the consumer's purchase (i.e., the recommender's status as an opinion leader)?

- How was the product purchased by the consumer?

- What risks was the consumer concerned about when they decided to purchase the product?

\section{ANALYSIS}

Upon completion and analysis of this data, the following themes were identified.

\section{Use of Social Media}

Respondents for this survey were active participants in social media. Respondents were asked to discuss which type of social media they were using when they received the recommendation that spurred them to purchase the product. From the total of all responses, 59\% of all respondents were using Facebook as their social media tool when they received a product recommendation. $37 \%$ of all users were using Twitter, which was a surprising result given Twitter's relative newness to the social media world in spite of its rapid growth (Janusz 2009). More surprisingly, for users under the age of 22, Twitter was the tool used most frequently to get their product recommendation $(52 \%)$. This result paints an interesting picture of perhaps a shifting trend in social media, in which younger consumers seem to be seeking a more instantaneous model of social media than can be provided by Facebook. 
As one respondent commented, "....we have Facebook so we can show pictures, but who cares about a status update made two days ago." (Female, 19)

\section{Type of Product recommended}

Respondents were then asked to discuss the type of product (good or service) that they purchased and information about the cost of that item. One of the most surprising findings of this research study was the surprising dyadic split between low cost (under \$20) and high cost (over \$200) items. $41 \%$ of the items mentioned in this study were under $\$ 20$, and another $38 \%$ of items mentioned were over $\$ 200$. In essence, our results were indicating that consumers were easy spurred by the quick and easy purchase (e.g., a friend recommends a cheap item costing $\$ 5$ and the individual instantly purchases it) or consumers were swayed by the recommendation on a larger purchase.

For smaller cost purchases, a common theme was “....it only cost $\$ 4$ and [name of friend] thought it was good so I went ahead and purchased it as well" (male, 18, food item coupon).

For larger purchases, a common theme was "...I have been looking at TVs for over a year, but this was the second person recommending this item so I went ahead and bought it." (male, 42, television).

Respondent data was also analyzed to investigate the split between purchasing a "good" versus purchasing a "service." Data indicates that the purchase of these items was split relatively evenly between consumers, with 58\% of items purchased being goods and $41 \%$ of the items being services.

\section{Purchase Location}

This research also investigated the idea of "clicking through" the recommendation from the social media to directly purchase the item. This research asked a series of questions regarding "how" the consumer decided to purchase the item once the recommendation was given. We were curious to see if a social media recommendation resulted in an immediate purchase or a delayed purchase, and we were curious to see if the consumer "clicked through" the recommendation to directly make the purchase (i.e., the recommender mentioned an item with a direct URL link, and the purchaser clicked on the link to purchase the item).

A surprising result of this item was the lack of "click through" for consumer purchases. Only $9 \%$ of consumers purchased an item directly through the link. Instead, most consumers would read the recommendation, spur interest in buying the item, but then purchase the item through a more familiar website.

“....I bought the vampire series books, but I have done all of my previous purchases through Amazon.com so I just logged off and went to that site to buy" (female, 29).

A less surprising result was the time spent post purchase for the consumer to buy the item. Typically, the consumer spent just a few days (average 3.2 days) at most before purchasing the item, and more than $2 / 3$ rds of the respondents purchased the item within 24 hours. This result is indicative of the "buy it now" mentality associated with social media and the internet; that is, if consumers have the means and desire to buy an item, they do not wait to purchase.

"My friend recommended a movie that he liked so I just went to the site, purchase(d) tickets, and went and saw it that evening with my girlfriend" (male, 21).

\section{Who is recommending?}

Perhaps the most surprising element of this research study was the idea of the "opinion leader" within marketing literature (e.g., Kratzer and Lettl 2009), and the very small role that concept played in this study. An opinion leader is someone who is deemed to have knowledge or expertise in a specific area while also sharing similar traits with the other individual (Rogers 1982). In previous marketing literature, it would generally be 
assumed that people would seek, and be influenced by, the opinion of people of this nature. However, only $11 \%$ of the consumers participating in this study made the decision to purchase the item based on the recommendation of someone they would consider an opinion leader. Nearly 4 times as many consumers, or approximately $42 \%$, purchased the item based on a recommendation of someone that they said they did not know very well (2.5 average on a 7 point likert scale). This indicates that for most participants in our study, getting a recommendation from "anyone" was considered credible whether or not the person actually had credibility.

“....I have over 2,000 friends so I don't even really know half of them, but I purchased the item anyways." (female, 22)

This surprising result is best explained through the advent and extensive use of message board reviews for products and news articles (e.g., Woo, An, and Cho 2008). Individuals now commonly look to reviews and message boards for information when they typically do not know the individuals on those review boards. Websites like tripplanner.com are examples of people making purchases for travel when they are receiving recommendations from unknown people rather than opinion leaders.

\section{Risks associated with purchasing:}

Data for this research study also looked at the risks associated with making purchases in an online environment. Respondents were asked to discuss their concerns about purchasing an item with regard to cost, time, need, use, and safety of purchasing an item online (e.g., Ling et. Al 2011). The largest issue of concern for this series of questions was with the question "would [item] work as promised." In this study, $36 \%$ of participants were worried that the item they were purchasing would not work as promised by the recommender. We believe the relatively large percentage of concern with this question links directly to this issue of the recommender being someone that the purchaser does not know well. When a consumer in this study bought an item based on a recommendation from a purchaser that was not considered to be an opinion leader, it is not surprising that there was concern with purchasing the item.

"I ended up buying tickets to the Blue Man Group show, which also meant that I had to make travel arrangements. I was worried that I wasn't going to like the show as much as my friend did even though he recommended it." (male, 38)

\section{SUMMARY AND DIRECTIONS FOR FUTURE RESEARCH}

While the field of social media has become an emerging area of research within the business discipline, there still exists uncertainty regarding the extent of the role that various forms of social media has on consumer purchase, and what items the consumers are purchasing. The purpose of this research, therefore, was to investigate the different types of purchase behavior being found from individuals buying items based on social media.

Our results indicate that consumers are buying either very inexpensive, or very expensive items, and are doing so based on recommendations from people they would not consider "opinion influencers or leaders". This surprising result indicates that firms can influence future purchases, perhaps, by encouraging their users to post on various forms of social media. For instance, firms could use discounts or incentives to have consumers recommend their product via social media if that recommendation led to future purchases by their connected friends.

In addition, results indicate a slow shift from more traditional forms of social media like Facebook to quicker types of social media like Twitter. Numerous respondents indicated their desire for information now, not even a day or two old, and this research indicates a shift towards that form of social media which is consistent with general themes of today's social media. For businesses, this could indicate that funding allocation might be better served on this type of social media format as opposed to advertisements on a more stagnant media like Facebook.

There exists numerous opportunities for future research within this area. First, future research could investigate more specifically the types of products that consumers could, or could not, be motivated to purchase from their social media. For instance, researchers could conduct an experiment in which consumers are presented 
with various items that have been recommended via social media to see what types of products they would, or would not, consider purchasing in that environment. Second, future research could be expanded to a larger pool of subjects representing more of an international population since a large percentage of social media users are found outside the United States. For instance, a second study could draw upon a pool of non-US citizens and then data between both pools could be compared.

\section{AUTHORS INFORMATION}

Lukas P. Forbes, Ph.D., Associate Professor of Marketing, Western Kentucky University, 1906 College Heights Blvd \#21059, Bowling Green, KY 42101 USA. E-mail: Lukas.Forbes@wku.edu (Corresponding author)

Eve M. Vespoli, MBA, 16980 South Meadows Circle, Strongsville, Ohio 44136 USA.

\section{REFERENCES}

1. Flanagan, J.C. (1954). The critical incident technique. Psychological Bulletin, 51( July) 327-358.

2. Greer, C. and Ferguson, D. (2011). Using Twitter for promotion and branding: A content analysis of local television twitter sites. Journal of Broadcasting \& Electronic Media, 55(2) 198-214.

3. Janusz, T. (2009). Marketing on Social Networks: Twitter, MySpace and Facebook Demystified", Key Words, 17 (4) 124-125.

4. Kratzer, J and Lettl, C. (2009). Distinctive Role of lead users and opinion leaders in social networks of schoolchildren. Journal of Consumer Research, 36(4) 646-659.

5. Ling, K, Daud, D., Piew, T., Keoy, K, and Hassan, P. (2011). Perceived risk, perceived technology, online tryst for the online purchase intention in Malaysia. International Journal of Business and Management, 6(6), 167-182.

6. Ojala, M. (2012). Minding your own business: social media invades business research. Online, 34 (4) 5153.

7. Ostrow, A. (2010). It's Official: Facebook Passes 500 Million users. http://mashable.com/2010/07/21/facebook-500-million-2

8. Plangger, K. (2012). The power of popularity: How the size of a virtual community adds to a firm's value. Journal of Public Affairs, 12(2) 145-153.

9. $\quad$ Rogers, E. (1982). Diffusion of Innovations. New York: Free Press.

10. Towner, T and Dulio, D. (2012). New Media and Political Marketing in the United States: 2012 and beyond. Journal of Political Marketing, 11(1/2) 95-119.

11. Vericat, J. (2010). Accidental Activists: Using Facebook to drive change. Journal of International Affairs, 64 (1) $177-180$.

12. Woo, C., An, S., Cho, S. (2009). Sports PR in Message Boards on Major League Baseball Websites. Public Relations Review, 34(2) 169-175. 
NOTES 